\title{
Electrically conductive acrylic pressure-sensitive adhesives containing carbon black
}

\author{
Zbigniew Czech ${ }^{1}$, Robert Pełech ${ }^{1}$, Agnieszka Kowalczyk ${ }^{1}$, Arkadiusz Kowalski ${ }^{1}$, Rafał J. Wróbel ${ }^{\mathbf{2}}$ \\ 1 West Pomeranian University of Technology, Szczecin, Institute of Chemical Organic Technology, ul. Pułaskiego 10, \\ 70-322 Szczecin, Poland \\ ${ }^{2}$ West Pomeranian University of Technology, Szczecin, Institute of Chemical Technology and Environmental Engineering, \\ ul. Putaskiego 10, 70-322 Szczecin, Poland \\ "Corresponding author: psa_czech@wp.pl
}

\begin{abstract}
Acrylic pressure-sensitive adhesives (PSA) are non electrical conductive materials. The electrical conductivity is incorporated into acrylic self-adhesive polymer after adding electrically conductive additives like carbon black, especially nano carbon black. After an addition of electrical conductive carbon black, the main and typical properties of pressure-sensitive adhesives such as tack, peel adhesion and shear strength, are deteriorated. The investigations reveals that the acrylic pressure-sensitive adhesives basis must be synthesised with ameliorated initial performances, like high tack, excellent adhesion and very good cohesion. Currently, the electrical conductive solvent-borne acrylic PSA containing carbon black are not commercially available on the market. They are promising materials which can be applied for the manufacturing of diverse technical high performance self-adhesive products, such as broadest line of special electrically conductive sensitive tapes.
\end{abstract}

Keywords: Acrylic pressure-sensitive adhesives, carbon black, electrical conductive materials.

\section{INTRODUCTION}

The development in the area of electronic conductive polymers with a high electronic conductivity was awarded the Nobel Prize for Chemistry in 2000 to Alan Heegre, Alan MacDiarmid, and Hideki Shirakawa. A variety of organic conducting polymer materials has now been developed for different applications in the industry. A number of synthetic routes have been developed for the preparation of conjugated polymers. The diversity has been driven by the desire to examine many different types of conjugated polymers like, polyacetylenes, polyphenylenes, polypyrroles, polythiophenes, poly (arylene vinylenes), and polyanilines and attempts to improve material properties. These six primary classes of conjugated polymers have been shown to exhibit high levels of electrical conductivity in the doped state. In addition, a number of multicomponent materials, usually polymer blends and composites have been prepared in which at least one of the components is a conducting materials ${ }^{1-4}$.

However, these conjugated polymers are not suitable for pressure-sensitive adhesive films and their electrical conductivity is too low to be applied for important and typical applications in electronic industry (Fig.1) ${ }^{1}$.

The key feature of the electrically conductive organic polymers is the presence of conjugated bonds with $\pi$-electrons delocalized along the polymer chains. In the undoped form, the polymers are either insulating or semiconducting with a large band gap. The polymers are converted to the electrically conductive or doped forms via oxidation or reduction reactions that form delocalized charge carriers. Charge balance is accomplished by the incorporation of an oppositely charged counter ion into the polymer matrix. The conductivity is electronic in nature and no concurrent ion motion occurs in the solid state. Most applications of conducting polymers utilize their electronic properties, but some special applications (battery or sensor electrodes) exploit their ionic properties ${ }^{5-6}$.
In the last sixty years, pressure-sensitive adhesives acrylics have made tremendous strides from what was virtually a black art to what is now a sophisticated science. Larger manufacturers of pressure-sensitive adhesive articles and their even larger suppliers now use very expensive equipment to study pressure-sensitive adhesive behavior: tack, peel adhesion and shear strength.

The addition of conductive fillers such as metal particles (copper, aluminum, silver), special modified carbon black, carbon fibers, metalized glass spheres and fibers allow the development of electrically conductive polymers with electrical conductivity between $10^{-2}$ and $10^{2} \mathrm{~S} / \mathrm{cm}$. This relatively high conductivity is the result of percolation of conducting filler particles in an insulating matrix or tunneling between the particles ${ }^{7}$. Electrically conductive pressure-sensitive adhesives are not commercially available on the market. They can be utilized for the manufacturing of diverse technical self-adhesive products, such as broadest line of electrically conductive sensitive tapes. It is well known that acrylic pressure-sensitive adhesives are generally considered as non electrical conductive materials. There is the practical requirement for the development of PSA, including special suitable self-adhesive polymers and their modification through an addition of electrical conductive fillers. From the evaluated PSA, the best performances were achieved using acrylic PSA $^{8-11}$.

The goal of this work was the manufacturing of electrically conductive solvent-borne acrylic PSA with high application performances such as high tack, high peel adhesion and excellent shear strength which can be widely applied as electrically conductive self-adhesive products, such as carrier free transfer, single sided or double side tapes on an industrial scale. In the production of electrically conductive pressure-sensitive adhesives, and electrically conductive tapes, it is desirable to employ high performance pressure-sensitive adhesives. 


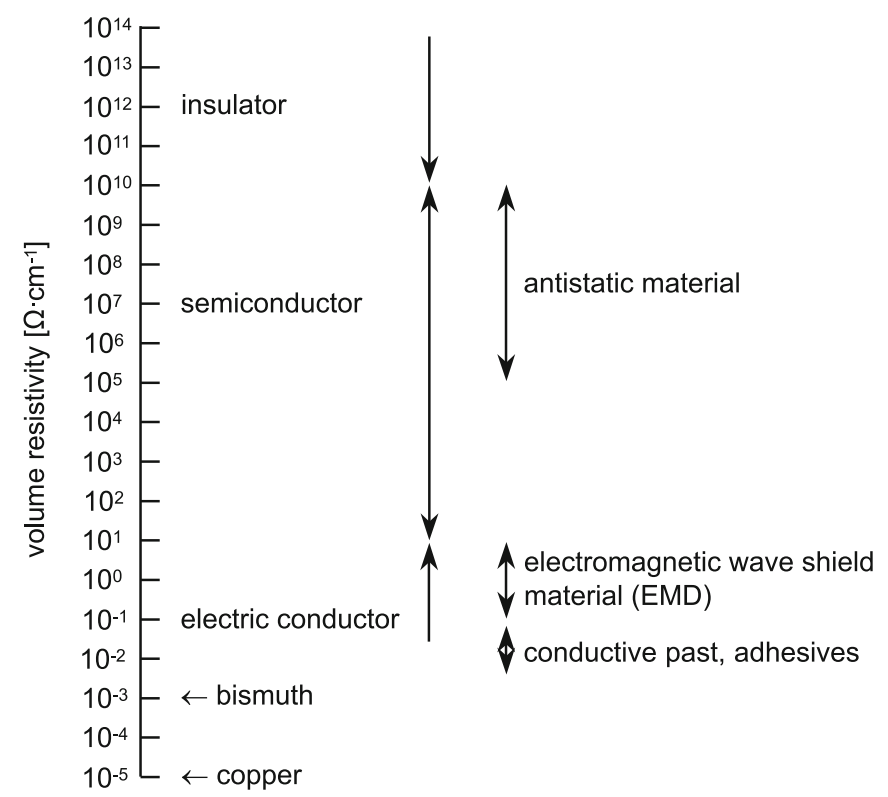

additive materials

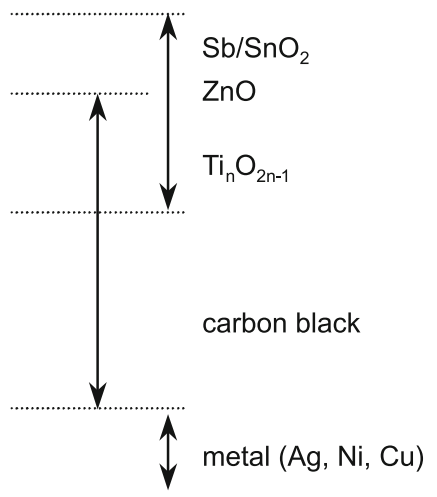

Figure 1. Electrical conductivity of diverse materials

\section{EXPERIMENTALS}

\section{Evaluation of molecular weight and viscosity}

The viscosity of the synthesized solvent-borne acrylic PSA was determined with a Rheomat RM 189 from Rheometric Scientific, with spindle No 3 at $23^{\circ} \mathrm{C}$. The molecular weight studies were performed in tetrahydrofurane with a liquid chromatography LaChrom system: RI Detector L-7490 and LaChrom UV Detector L-7400 from Merck-Hitachi, equipped with a PLgel $10^{6} \AA$ column from Hewlett-Packard.

\section{Synthesis of acrylic PSA}

The solvent-borne acrylic PSA as a basic polymer for electrically conductive PSA were synthesized in ethyl acetate with 50 wt.\% polymer content by using of 96 wt.\% 2-ethylhexyl acrylate and $4 \mathrm{wt} . \%$ acrylic acid at presence of 0.1 wt. $\%$ radical starter AIBN at temperature of about $78^{\circ} \mathrm{C}$. All components were available from BASF (Germany).

\section{Modification of synthesized acrylic PSA}

The synthesized acrylic PSA was modified using 40 wt.\% resin Dertophene T115 (DRT, France) and 10 wt. $\%$ resin Tragum 2331WS (Tramaco, Japan) according to polymer content to ameliorate the adhesiveness properties like tack and peel adhesion and crosslinked with 0.5 wt.\% aluminum acetylacetonate (DuPoint, USA). The properties of filler-free unmodified and modified acrylic PSA were demonstrated in the Tab. 1.

\section{Addition of electrical conductivity fillers}

The described trials were conducted using a special grade of electro-conductive nano carbon black Vulcan XC-72 R (Cabot, USA) with a particle size equal to $30 \mathrm{~nm}$ in amounts between $3 \mathrm{wt} . \%$ and $40 \mathrm{wt} . \%$ with reference to polymer content. The carbon black nano- filler were dispersed into the adhesive solution using a dissolver at about $10000 \mathrm{rpm}$. Naturally, the addition of such fillers degrades the adhesive properties of the material, such as the tack and peel adhesion.

\section{Measurement of PSA properties}

The solvent-borne acrylic PSA with or without carbon black Vulcan XC-72 R are coated directly with $90 \mathrm{~g} / \mathrm{m} 2$ on a polyester film and after drying for $10 \mathrm{~min}$ at $105^{\circ} \mathrm{C}$ in drying canal. The typical properties of PSA such as tack peel adhesion and shear strength and the influence of conductive fillers concentration on these adhesives properties were determined by standard A.F.E.R.A. (Association des Fabricants Europeens de Rubans Auto-Adhesifs) procedures. Exact details can be found in AFERA 4015 (tack), AFERA 4001 (peel adhesion), and AFERA 4012 (shear strength).

\section{Electrical conduction properties}

The electrical conductivity $\varsigma$ of a material, which is the inverse of its specific resistivity $\varrho$, is a measure of a material's ability to transport electrical charge. The material intrinsic properties resistivity and conductivity are independent of sample dimensions unlike as resistance, which depends on sample size. Electrical conductivity is commonly measured in units of $\mathrm{S} / \mathrm{cm}$. The most common method of measuring conductivity is known, described in a lot of technical literatures and international standardized $^{\mathbf{1 2 - 1 4}}$. Surface resistivity is determinated according to the DIN 53482 method.

\section{RESULTS AND DISCUSSION}

\section{Viscosity and molecular weight of acrylic PSA}

The synthesized solvent-borne acrylic PSA are characterized by the viscosity of $8100 \mathrm{mPa} \cdot \mathrm{s}$, weight average

Table 1. Properties of basic and resin modified acrylic PSA

\begin{tabular}{|c|c|c|c|c|c|c|c|c|c|}
\hline \multicolumn{5}{|c|}{ Basic acrylic PSA } & \multicolumn{5}{|c|}{ Resin modified acrylic PSA } \\
\hline \multirow[t]{2}{*}{ Tack } & \multicolumn{2}{|c|}{ Peel adhesion } & \multicolumn{2}{|c|}{ Shear strength } & \multirow[t]{2}{*}{ Tack } & \multicolumn{2}{|c|}{ Peel adhesion } & \multicolumn{2}{|c|}{ Shear strength } \\
\hline & $20^{\circ} \mathrm{C}$ & $70^{\circ} \mathrm{C}$ & $20^{\circ} \mathrm{C}$ & $70^{\circ} \mathrm{C}$ & & $20^{\circ} \mathrm{C}$ & $70^{\circ} \mathrm{C}$ & $20^{\circ} \mathrm{C}$ & $70^{\circ} \mathrm{C}$ \\
\hline $33.4 \mathrm{~N}$ & $35.7 \mathrm{~N}$ & $18.9 \mathrm{~N}$ & $90 \mathrm{~N}$ & $40 \mathrm{~N}$ & $40.1 \mathrm{~N}$ & $44.7 \mathrm{~N}$ & $14.5 \mathrm{~N}$ & $60 \mathrm{~N}$ & $16 \mathrm{~N}$ \\
\hline
\end{tabular}


molecular weight $\mathrm{M}_{\mathrm{W}}$ of $582000 \mathrm{~g} / \mathrm{mol}$, number average molecular weight $\mathrm{Mn}$ of $165000 \mathrm{~g} / \mathrm{mol}$ and polydispersity $\mathrm{P}_{\mathrm{d}}$ of $3.5\left(\mathrm{P}_{\mathrm{d}}=\mathrm{M}_{\mathrm{W}} / \mathrm{Mn}\right)$.

\section{Adhesive and cohesive properties}

The main properties of the filler-free unmodified and modified basic acrylic PSA such as tack peel adhesion (at 20 and $70^{\circ} \mathrm{C}$ ) and shear strength (at 20 and $70^{\circ} \mathrm{C}$ ) are shown in Table 1.

After the addition of resins 40 wt.\% Dertophene T115 and 10 wt. \% resin Tragum 2331WS and 0.5 wt. $\%$ crosslinker aluminum acetylacetonate, the adhesiveness properties such tack and peel adhesion rapidly increase, of course on the cost of cohesiveness properties (shear strength), especially at $70^{\circ} \mathrm{C}$.

The amount of carbon black filler Vulcan XC-72 R, ranging from 3 to $40 \mathrm{wt} . \%$, determines the tack, peel adhesion, shear strength and electrically conductivity of solvent-borne acrylic PSA formulations.

The measurement properties values of solvent-borne acrylic PSA characterized for several adhesive and cohesive performance were illustrated in Figures 2-4.

The addition of carbon black Vulcan XC-72 R to solvent-borne acrylic PSA reduces strongly tack and peel adhesion level. After the addition of a small amount of carbon black, the acrylic PSA begins to crosslink, causing its structure to become compact and its tack and

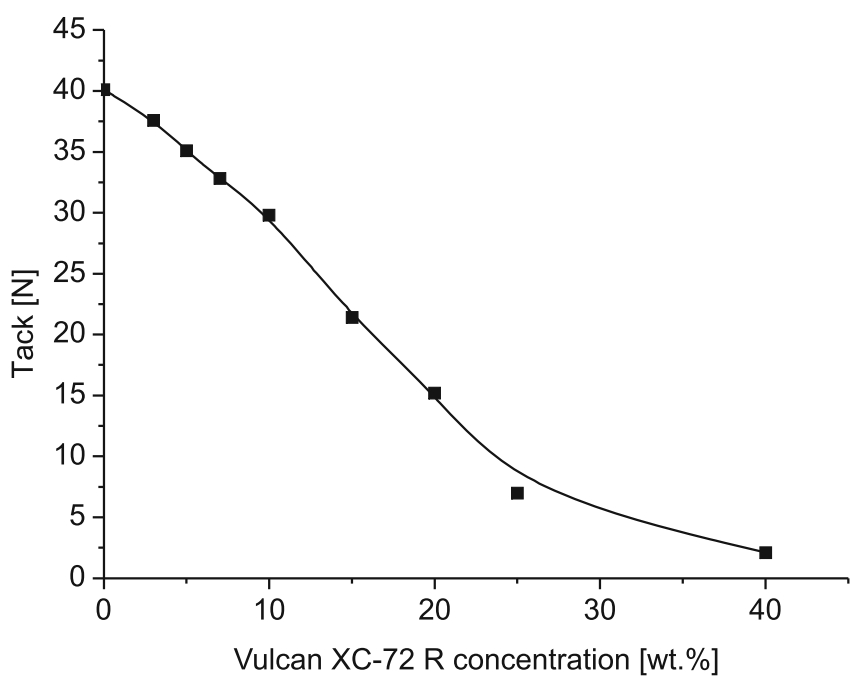

Figure 2. Tack of acrylic PSA as a function of carbon black content

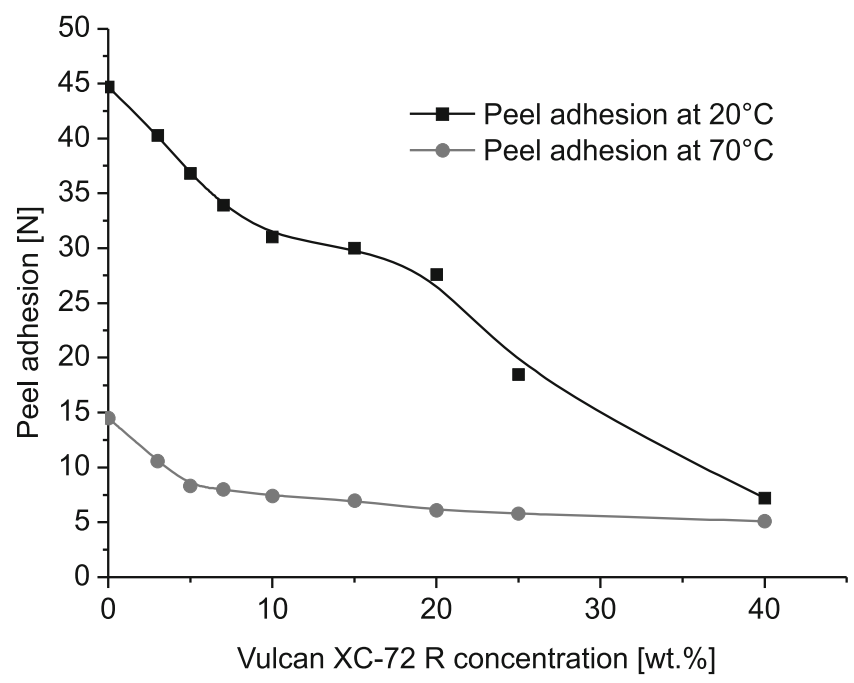

Figure 3. Peel adhesion of acrylic PSA containing carbon black

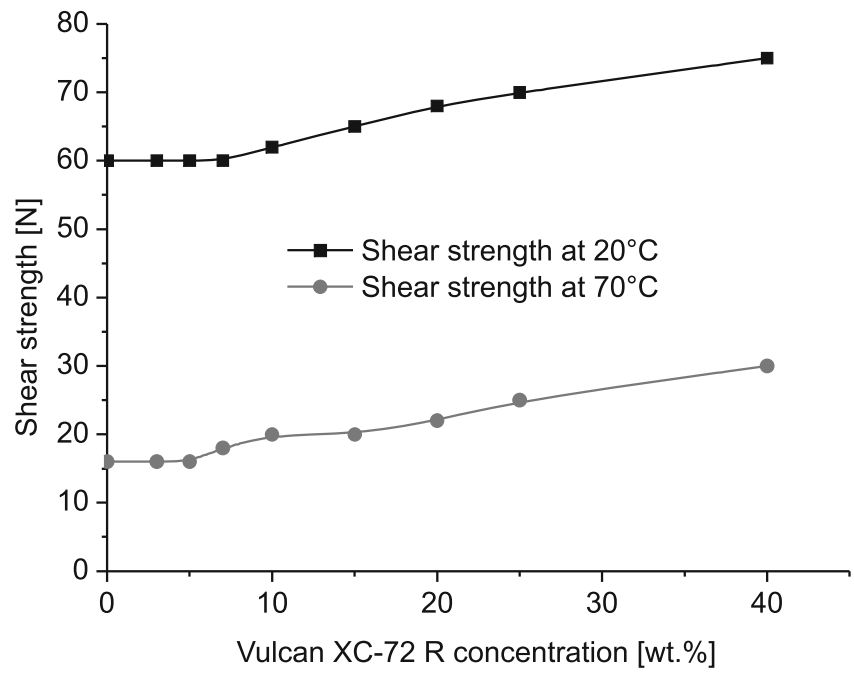

Figure 4. Shear strength of acrylic PSA containing carbon black

peel adhesion to decrease. This decrease in tack and peel adhesion with increasing carbon black content due to the increased cross-linking degree is opposed by the tendency of higher filler contents to a reduction of tack and peel adhesion level.

Fig. 4 is a graph which illustrates the relationship between the varying carbon black content and the shear strength, measured at $20^{\circ} \mathrm{C}$ and $70^{\circ} \mathrm{C}$, of acrylic PSA.

It should be noted that an almost linear relationship exists between the shear strength values experimentally obtained of solvent-borne acrylic PSA and the carbon black concentration. The addition of nano filler carbon black Vulcan XC-72 R ameliorates the cohesion, measured as shear strength, of modified conductive adhesive layers. It is a typical effect observed for polymer matrix containing nano fillers.

\section{Electrical conductivity of acrylic PSA containing carbon black filler}

The addition of electrical conductive carbon black to the solvent-borne acrylic PSA made it possible to obtain a self-adhesive material with electrically conductivity. The dependence of the electrical conductivity of acrylic PSA containing carbon black Vulcan XC-72 R on the filler content is listed in Table 2 and shown in Fig. 5. The reported values represent the average of the three readings. The results show the expected trend of increasing electrical conductivity with increasing the carbon black filler loading.

The electrical conductivity in the case of about 25 wt.\% carbon black Vulcan XR-72 R shows a relatively high and stable level (Fig. 5). The electrical conductivity of the acrylic PSA with 25 wt.\% and higher concentration of carbon black was relatively high, about $16 \mathrm{~S} / \mathrm{cm}$. For higher concentration of carbon black the electrical conductivity values of self-adhesive layers stayed on the similar high level, as a result of a typical percolation effect.

As the carbon black concentration increased further, the electrical conductivity of the self-adhesive layers increased significantly. The contact points of many sphere particles such improving without any doubt the electrical conductivity of the developed acrylic pressure-sensitive adhesives layers. In fact, no separation of the conductive carbon black each over in the solvent-borne acrylic PSA 
Table 2. Electrical and optical properties of acrylic PSA containing carbon black filler

\begin{tabular}{|c|c|c|c|}
\hline $\begin{array}{c}\text { Vulcan } \\
\text { XC-72 R } \\
{[\mathrm{wt} . \%]}\end{array}$ & $\begin{array}{c}\text { Surface } \\
\text { resistivity } \\
{[? \cdot \mathrm{cm}]}\end{array}$ & $\begin{array}{c}\text { Electrical } \\
\text { conductivity } \\
{[\mathrm{S} / \mathrm{cm}]}\end{array}$ & $\begin{array}{c}\text { Quality of PSA layer } \\
\text { surface }\end{array}$ \\
\hline 0 & $10^{11}$ & $10^{-11}$ & very good \\
\hline 3 & $10^{11}$ & $10^{-11}$ & very good \\
\hline 5 & $10^{11}$ & $10^{-11}$ & very good \\
\hline 7 & $10^{11}$ & $10^{-11}$ & very good \\
\hline 10 & $10^{9}$ & $10^{-9}$ & good, acceptable \\
\hline 15 & 5 & 0.2 & good, acceptable \\
\hline 20 & 0.125 & 8 & good, acceptable \\
\hline 25 & 0.0625 & 16 & good, acceptable \\
\hline 40 & 0.0588 & 17 & good, acceptable \\
\hline
\end{tabular}

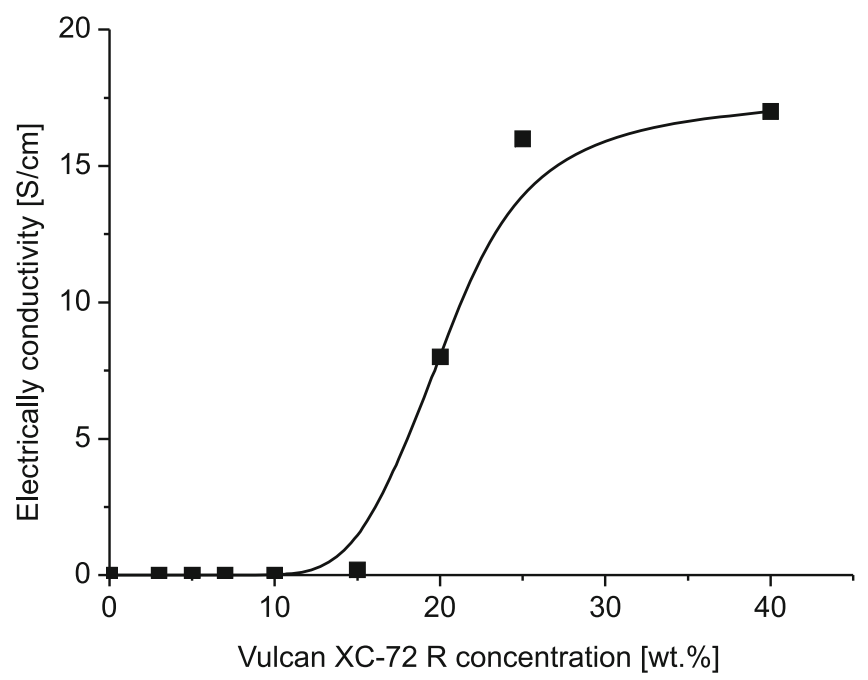

Figure 5. Electrical conductivity of acrylic PSA as a function of carbon black content

is very effective on forming the percolation.

In Figure 6 the structure of the acrylic PSA films surfaces, containing carbon black XC-72 R in amount of 20 and 25 wt. $\%$, carried out under optical microscope Nikon Eclipse E600 in 40 blow-up was shown.

Some distinct differences can be discerned between the fracture sites in PSA layer containing $20 \mathrm{wt} . \%$ ande 25 wt.\% of carbon black Vulcan XC-72 R. The PSA layer with 20 wt.\% Vulcan XC-72 R clearly reveals carbon

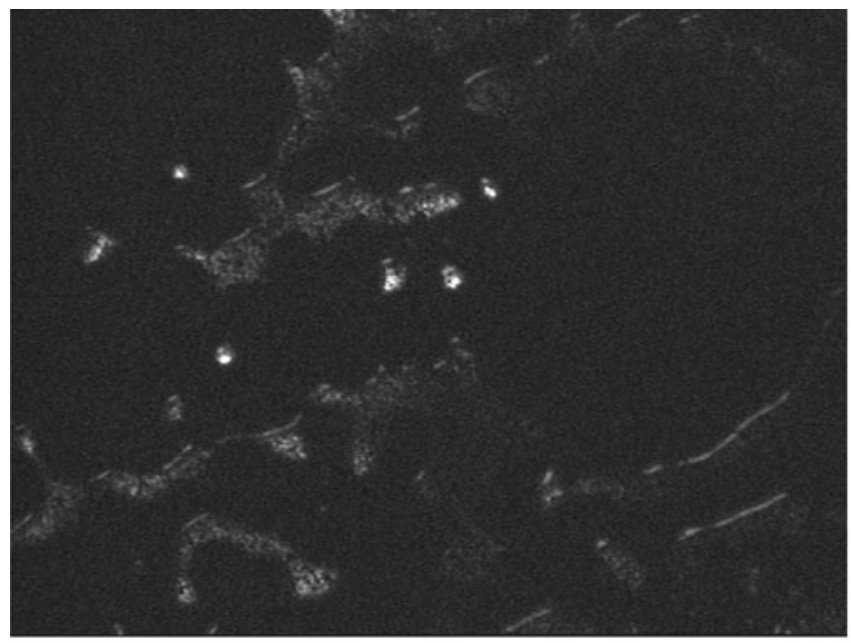

20 wt. \% Vulcan XC- 72 R black aggregates as if PSA layer containing 25 wt. $\%$ Vulcan XC-72R. To understand these observations the morphology of carbon black has to be considered.

\section{Stability of solvent-borne acrylic PSA containing carbon black Vulcan XC-72 R}

The electrically conductive solvent-borne acrylic PSA containing between 20 and 40 wt.\% Vulcan XC-72 R remained optically homogeneous for several hours and were stable for longer than 30 days (Fig. 7). The evaluated viscosities are listed in Table 3. Prior to the coating process the adhesives containing the filler had to be thoroughly mixed. The pressure-sensitive adhesive layers containing carbon black were black-coloured.

As it can be seen in Fig. 7, the viscosities of solventborne acrylic PSAs containing a high contents of carbon black filler Vulcan XC-72 R between 20 and 40 wt.\% according to polymer content are relatively stable and the resulted modified electrically conductive acrylic PSA can be, after 1 month, easily coated on adhesive carrier or directly on carrier material to manufacture electrically conductive self-adhesive products. It is very easy to stabilize the acrylic PSAs containing carbon black Vulcan XC-72 R. The pot-life of such acrylic adhesives has been longer than a one month. After one month of the storage time of the best stabilization has been observed

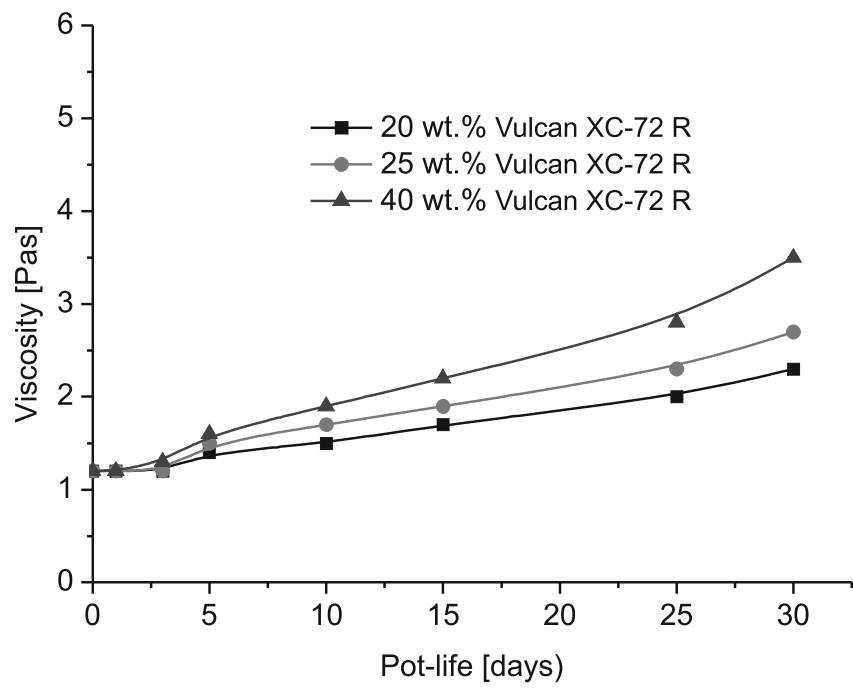

Figure 7. Pot-life of selected solvent-borne acrylic PSAs containing carbon black

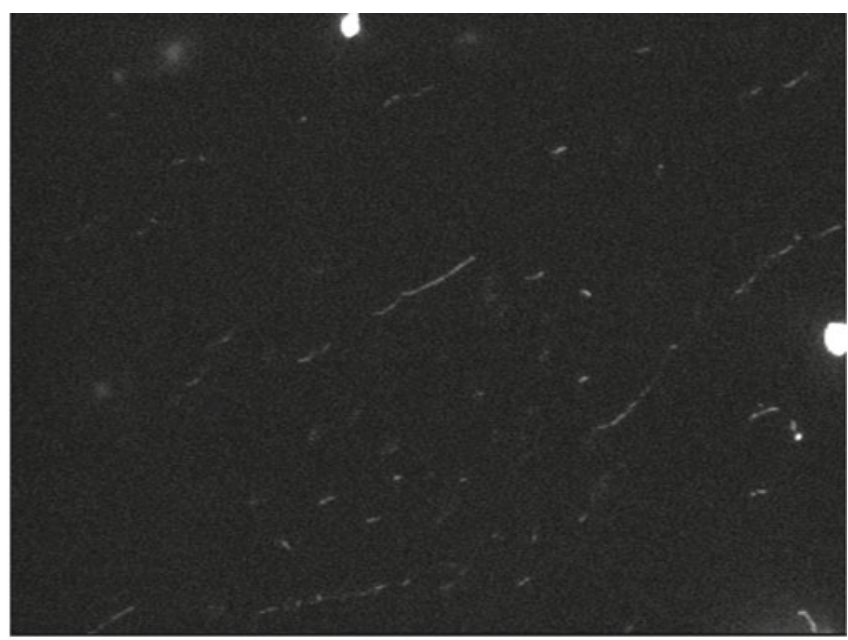

25 wt. \% Vulcan XC-72 R

Figure 6. Acrylics PSA layers containing 20 and 25 wt.\% of chosen carbon black filler 
Table 3. The pot-life of solvent-borne acrylic PSAs containing Vulcan XC-72 R

\begin{tabular}{|c|c|c|c|c|c|c|c|c|c|}
\hline $\begin{array}{c}\text { Carbon } \\
\text { black }\end{array}$ & \multicolumn{10}{|c|}{ Viscosity [Pa-s] after........days } \\
\hline [wt.\%] & 0 & 1 & 2 & 3 & 5 & 10 & 15 & 25 & 30 \\
\hline 20 & 1.2 & 1.2 & 1.2 & 1.2 & 1.3 & 1.4 & 1.6 & 1.9 & 2.3 \\
25 & 1.2 & 1.2 & 1.2 & 1.3 & 1.5 & 1.7 & 1.9 & 2.2 & 2.7 \\
30 & 1.2 & 1.2 & 1.2 & 1.3 & 1.7 & 1.9 & 2.1 & 2.8 & 3.6 \\
\hline
\end{tabular}

for solvent-borne acrylic PSA, which contained $20 \mathrm{wt} . \%$ carbon black filler. Using isopropyl alcohol stabilizer can prolong the pot-life of the solvent-borne PSA solutions containing tested carbon black, even up to 6 months.

\section{CONCLUSIONS}

The addition of carbon black filler to solvent-borne acrylic PSA reduces tack and peel adhesion level of selfadhesive layers. The electrically conductive solvent-borne acrylic pressure-sensitive adhesives containing carbon black remained optically homogeneous and were blackcoloured. The electrical conductivity of the acrylic PSA layers filled with $25 \mathrm{wt} . \%$ and higher concentration of Vulcan XC-72 R shows a relatively high level of $16 \mathrm{~S} /$ $\mathrm{cm}$. The percolation threshold was observed at 25 to 40 wt.\% fillers resulting in the electrical conductivity from about 16 to $17 \mathrm{~S} / \mathrm{cm}$. For higher concentration of carbon black, the electrical conductivity values of self-adhesive layers stayed on the similar acceptable level. Prior to the coating process the adhesives containing the filler had to be thoroughly mixed. It is very easy to stabilize the solvent-borne modified acrylic PSA containing carbon black. Their pot-life is longer than a one month. Using isopropyl alcohol stabilizer helped to prolong the potlife of the solvent-borne PSA containing carbon black Vulcan XC-72 R even up to 6 months. Electro-conductive acrylic PSA can be also produce by dispersing electro conductive particles in an electrically insulating matrix. Electrically conductive tapes play an important role in the electronics industry, electrostatic discharge protection and electromagnetic radiofrequency interference (EMI/ FRI) protection. The new developed electrically conductive tape is ideal for interconnection of flexible circuits (flex), rigid printed circuit boards or LCD screens.

\section{LITERATURE CITED}

1. Saurer, W. (1991) Intrinsically conductive polymers. Kunststoffe, 81, 694-699.

2. Nasser, K. (2004) Electroplating: basic principles, processes and practice. Elsevier, Oxford.

3. Skotheim, T. \& Reynolds, J. (2007) Handbook of conducting polymers third edition conjugated polymers theory, synthesis, properties, and characterization. Taylor \& Francis Group, LLC, London.

4. Shen, L., Wang, F., Yang, H. \& Meng, Q. (2011) The combined effects of carbon black and carbon fiber on the electrical properties of composites based on polyethylene or polyethylene/polypropylene blend. Polym. Test. 30, 442-448. DOI:10.1016/j.polymertesting.2011.03.007.

5. Naarmann, H. (1988) Die elektrochemische Polymerisation. Ein interessantes Prinzip zur Synthese von elektrisch leitfähigen Polymeren. Angew. Makromol. Chem. 162 1-17. DOI: 10.1002/ apmc.1988.051620101.

6. Mair, H.J. \& Roth, S. (1989) Elektrisch leitende Kunststoff, Carl Hanser Verlag, München-Wien.

7. Czech, Z. \& Klementowska-Witkowska, P. (2007) Electrical conductive acrylic pressure-sensitive adhesives. Pitture e Vernici European Coatings, 11, 101-108.

8. Danes, F., Garnier, B. \& Dupuis, T. (2005) Non-uniformity of the filler concentration and of the transverse thermal and electrical conductivities of filled polymer plates. Compos. Sci. Technol. 65, 945-951. DOI:10.1016/j.compscitech.2004.10.020.

9. Poh, B.T., Giam, Y.F. \& Yeong, F.P. (2010) Tack and shear strength of adhesives prepared from styrene-butadiene rubber (SBR) using gum rosin and petro resin as tackifiers. J. Adhesion . 86, 844-856. : DOI: 10.1080/00218464.2010.498734.

10. Gdalin, B.E., Bermesheva, E.V., Shandryuk, G.A. \& Feldstein, M.M. (2011) Effect of Temperature on Probe Tack Adhesion: Extension of the Dahlquist Criterion of Tack. J. Adhesion, 87, 111-138. DOI:10.1080/00218464.2011.545325.

11. Bai, Y.P., Zhao, L. \& Shao, L. (2010) Hybrid emulsifiers enhancing polymerization stabilities and properties of pressure sensitive adhesives. J. Appl. Polym. Sci. 115, 1125-1130. DOI: 10.1002/app.31211.

12. Novak, I., Krupa, I. \& Chodak, I. (2003)Analysis of correlation between percolation concentration and elongation at break in filled electroconductive epoxy-based adhesives. Eur. Polym. J. 39, 585-592. DOI:10.1016/S0014-3057(02)00271-9.

13. Feller, J.F. \& Grohens, Y. (2005) Electrical response of Poly(styrene)/carbon black conductive polymer composites (CPC) to methanol, toluene, chloroform and styrene vapors as a function of filler nature and matrix tacticity. Synthetic Met. 154, 193-196. DOI:10.1016/j.synthmet.2005.07.050.

14. Novak, I., Krupa, I. \& Janigowa, I. (2005) Hybrid electro-conductive composites with improved toughness, filled by carbon black. Carbon, 43, 841-848. DOI:10.1016/j. carbon.2004.11.019. 